\title{
OSTEOGÉNESIS IMPERFECTA Reporte de un caso
}

José Joaquín Suárez, MD;* Roy Riascos, MD, ** Rose Mary González, MD.***

\section{Resumen}

La osteogénesis imperfecta o enfermedad de Lobstein, es una alteración deformante ósea en la cual se afectan los genes que forman el colágeno. Se caracteriza clínicamente por la presencia de huesos deformes con múltiples fracturas patológicas, escleras azules e hipoacusia. Se divide en dos grupos principales, la forma letal o congénita y la tardía. Se presenta un caso interesante de este último que fue diagnosticado por ecografía intrauterina.

\section{Introducción}

La osteogénesis imperfecta es un grupo heterogéneo de enfermedades del colágeno caracterizado por mutaciones en los genes del colágeno que da lugar a huesos con múltiples fracturas. Esta afección en la mayoría de los casos es letal antes o en el momento del nacimiento. Se presenta el caso de un paciente de 6 años con un tipo muy poco frecuente no letal dentro del espectro de osteogénesis imperfecta. ${ }^{1,5,6}$

\section{Informe de caso}

Paciente de sexo femenino de 6 años, que consulta por primera vez a esta institución para control radiográfico de osteosíntesis del fémur derecho, realizada 30 días antes, secundaria a fractura patológica.

Como antecedente de importancia, se encuentra el diagnóstico de osteogénesis imperfecta realizada in-útero a la semana 14 del embarazo. Los hallazgos relevantes son disminución importante de la talla con deformidad y acortamiento (hipoplasia) de miembros superiores e inferiores, hipoacusia moderada y escleras azules.

\section{Imágenes diagnósticas}

La osteogénesis imperfecta es clínica y genéticamente un grupo de desordenes del colágeno que

Médico Radiólogo, **Residente III de Radiología, ***Residente I de Radiología, Fundación Universitaria de Ciencias de la Salud,

Hospital de San José, Bogotá, D.C., Colombia compromete los huesos, la piel, el oído interno, los ligamentos y los tendones. Se caracteriza por huesos frágiles y deformidad de los contornos en arco, escleras azules e hipoacusia.

Múltiples clasificaciones se han propuesto para ésta patología, basadas en hallazgos radiológicos , órganos afectados, momento de manifestación y forma de transmisión genética; en términos generales todas coinciden en que hay dos formas principales: congénita y tardía. ${ }^{1,2,3,4}$

La primera es la más grave de las dos, se puede diagnosticar in-útero y casi siempre es letal; puede ocasionar la muerte intrauterina o neonatal, y la causa más frecuente de ésta es la hemorragia intracraneana. $^{1,4}$

La forma tardía es menos severa, puede no observarse en el recién nacido y manifestarse al inicio de la de ambulación con fracturas secundarias a traumas leves. Es muy importante diferenciarla del maltrato infantil. En casos raros se puede llegar hasta la edad adulta presentando osteopenia, incluso puede haber mejoría de la fragilidad ósea con el aumento de la edad y es menos severa en las mujeres. ${ }^{1,4}$

\section{Signos radiológicos}

Hay tres tipos de presentaciones radiológicas: hueso delgado y frágil; hueso grueso y hueso quístico. La primera de ellas se reconoce en el útero o en el recién nacido. Las diáfisis óseas son de diámetro delgado y con disminución del grosor cortical, 
hay trabéculas óseas mal definidas con extremos gruesos y zonas de deformidad por múltiples fracturas; se pueden evidenciar líneas óseas densas en la

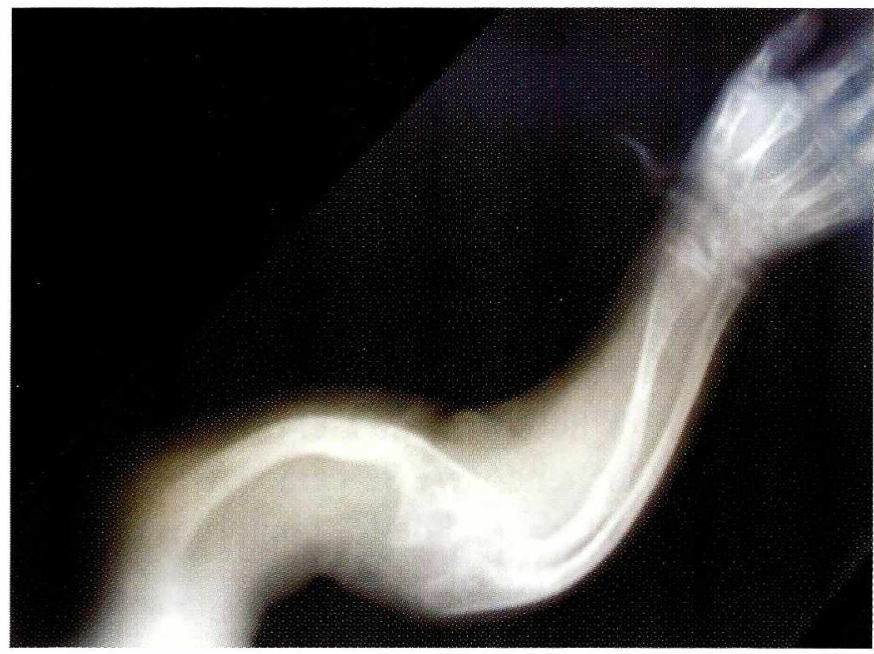

Figura 1. Proyección de radiología convencional del miembro superior izquierdo del paciente.

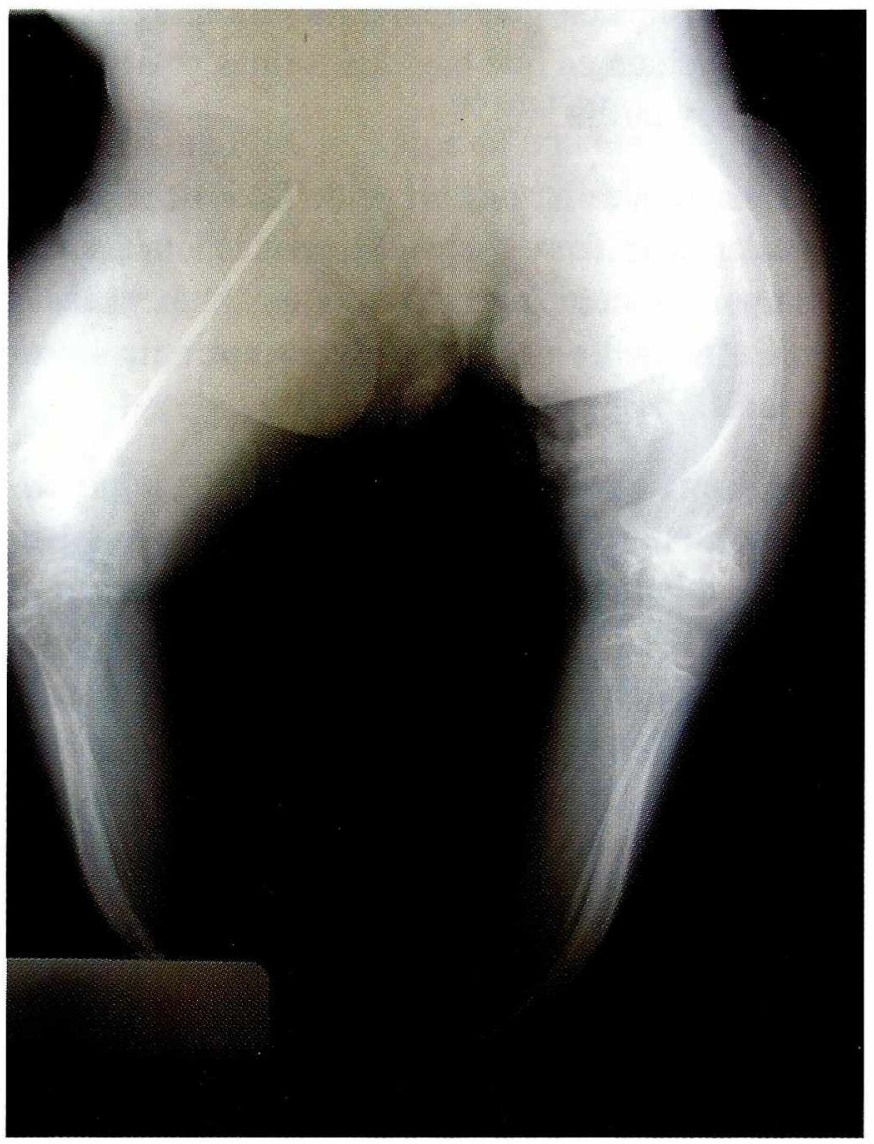

Figura 2. Proyección de radiología convencional de los miembros inferiores del paciente. En el fémur derecho se aprecia material de osteosíntesis. Nótese la disminución de la densidad ósea en forma generalizada, con huesos largos deformados en forma de arco. unión de la metáfisis con la epífisis por microfracturas a este nivel. Los huesos de la calota son lábiles por su subosificación con fisuras exageradamente amplias y fragmentación o presencia de múltiples huesos wornianos.

La variedad con hueso grueso presenta aumento del diámetro de la diáfisis de los huesos largos con deformidades en arco. La cortical se adelgaza con extremos distales anchos. Corresponde a mas del 80 $\%$ de los casos descritos.

La tercera forma de presentación es la menos frecuente se inicia en el nacimiento y es progresiva, observando múltiples áreas de tipo quístico en los huesos largos, que con el tiempo se deforman en arco. La cortical y la densidad ósea se encuentran disminuidas. Hay callos óseos con pseudoartrosis (principal manifestación clínica) y el diagnóstico de este tipo se confirma por la presencia de escleras azules., ${ }^{1,4}$

\section{Discusión}

Se presenta un caso interesante de osteogénesis imperfecta típica que fue diagnosticada in-útero, con características óseas de hueso delgado; la mayoría de estos pacientes fallecen durante la gestación o en el periodo neonatal. Dentro del espectro de esta enfermedad el caso estudiado es una presentación bastante rara, al considerar que la paciente tiene 6 años. Contrasta con la forma no letal que tiene manifestaciones radiológicas de hueso grueso o quístico y que pueden llegar a la edad adulta (Figuras 1 y 2).

\section{Referencilas}

1. Diagnostic ultrasound; Karoll M. Rumack, $2^{\mathrm{a}}$ ed, Vol 2; pgs: 2114-2116, 1223.

2. Pediatric X-Ray Diagnosis; John Caffey. $5^{\mathrm{a}}$ ed; pgs 853-857. 3. Imagin of Newborn, infant, and young child; Leonard E. Swischuck, $4^{\mathrm{a}}$ ed; pgs $802-804$.

4. Roentgen diagnosis of disease born; Jack Edeinken, Hodes. Pags: 149-159. Munoz C, Fillyra, Golbus MS. Osteogenesis imperfecta Tipo II: Prenatal sonographic diagnosis. Radiology 1990; 174: 181-185

5.Goldman AB, Davison D, Pavlov H, et all. "popcorn"calcifications: a prognostic sign in osteogenesis imperfecta. Radiology 1980; 136: 351-358. 